\title{
Reflections on a Critical Sociology of Networks
}

\author{
Charalambos Tsekeris
}

\author{
Research Centre for Greek Society, Academy of Athens, Athens, Greece, \\ tsekeris@gmail.com
}

\begin{abstract}
Social life is rife with networks of any kind. Nowadays, sociological concerns for networks, relations, associations, processes, mobilities, and flows are intensive and emblematic. This reflection takes "networks" and their multiple products as starting points for a new sociological imagination. It hence outlines a set of current theoretical and methodological issues for approaching the wide and diverse field of the sociology of networks in a critical manner, beginning from the analytical distinction between the critical and the normativefunctionalist sociology of networks. The paper concludes with reference to contemporary digital society and the critical use of network data (Big Data), that is, ever-larger quantities of information generated by human communicative interactions in social networking platforms and other web activities.
\end{abstract}

Keywords: Sociology of Networks, Relational Social Science, Human Complex Systems, Research Methods, Internet, Big Data, Power, Technology, Knowledge, Social Dynamics

Acknowledgement: This reflection presents personal views of the author. It is a modified version of the text of an inaugural address delivered at the International Interdisciplinary Congress "elife2016", which was held under the Auspices of H.E. the President of the Hellenic Republic Mr. Prokopios Pavlopoulos, in Plastiras Lake, Greece, June 23-26, 2016. It also pertains to an ongoing research activity that takes place within the Research Centre for Greek Society of the Academy of Athens, Athens, Greece. I would like to warmly thank Prof. Lily Stylianoudi (Director of the Research Centre for Greek Society of the Academy of Athens) as well as the anonymous reviewers for helpful thoughts and advice.

\section{Introduction}

Over the last few decades, the focus on networks has grown tremendously and signified an increasingly vibrant sociological area. Yet despite the promise of revitalising and unifying all sociological research under the banner of a theoretical interest in relationships, this area lacks a clear research trajectory and a coherent framework and rationale: "It is much easier to pull ideas and methods out of context if a field appears to others as a largely unorganized grab bag of measures, tools, and ideas" (Erikson $2013,220)$. The task of this paper is less concerned with developing a coherent or unified sociological theory of networks than with informing about some critical possibilities, which have yet to be explored in depth. ${ }^{1}$

In general, the (diverse) social network research tradition warns us against any theoretical or methodological attempt to "reify, hypostatise, and ultimately mystify

\footnotetext{
1 For Emily Erikson (2013, 220), this disturbing and persistent situation "can frustrate the efforts of individual researchers and impede the overall progress of the field. Sub rosa disagreements can lead important fields to drop out of top journals when the quality of work remains high but consensus is difficult to achieve".
} 
"society" (or some equivalent) as an entity distinct from the nexus of human interactivity which, properly speaking, comprises it" (Crossley 2015, 3). Drawing from the established work of classics, such as Tönnies (1957), Simmel (1950) and Moreno (1961), as well as from the quantitative "revolution" of the 1960s (Barnes 1969), Barry Wellman and Barry Leighton, in their Networks, Neighborhoods, and Communities: Approaches to the Study of the Community Question (1979), famously introduced a network analysis perspective on the social, pertaining to the search for social linkages, flows of resources, and spatial distributions. And in his latest book titled Networked (co-authored with Lee Rainie), Wellman extends this perspective to elaborate on our contemporary digital lives within networked operating systems which require from us to develop new "skills for handling problems", as well as to "actively network" and "forge alliances" (Rainie and Wellman 2012, 9). ${ }^{2}$

During the 1990s, we witnessed the emergence of different influential schools of thought and inquiry. Harrison White (1992) linked social networks to culture, identity, communicative interaction, agency and language, ${ }^{3}$ and Manuel Castells (1996) suggested that we live in a speedy "network society", in which information (that is, the key commodity) flows across time and space between loosely connected individuals and groups of people:

[...] dominant functions and processes in the information age are increasingly organized around networks. Networks constitute the new social morphology of our societies, and the diffusion of networking logic substantially modifies the operation and outcomes in processes of production, experience, power, and culture. While the networking form of social organization has existed in other times and spaces, the new information technology paradigm provides the material basis for its pervasive expansion throughout the entire social structure. (Castells 1996, 469)

2 In overall, Rainie and Wellman articulate a techno-fetishistic and techno-optimistic approach as to the direction of the current (disadvantageous) working conditions and social developments of late capitalism. According to the authors, people today experience more creative, self-directed and self-determined working conditions: "Many of the most technologically connected workers have jobs built around creative effort rather standardized paper pushing. This thrusts more autonomy and authority onto individual workers. Flexible arrangements with bosses, peers and subordinates encourage independent thinking and perhaps even creativity" (Rainie and Wellman 2012, 15-16).

${ }^{3}$ This also refers to a large group of authors around Harrison White, such as Peter Bearman, Ronald Breiger, Paul DiMaggio, Mustafa Emirbayer, David Gibson, Roger Gould, John Levi Martin, Ann Mische, John Padgett, and Charles Tilly (Fuhse 2015). In specific, Harrison White's Identity and Control (1992) triggered a long chain of seminal empirical studies on the central theoretical and methodological assumption that "a social network is a network of meanings" (White 1992, 67). This central assumption implies that the (reciprocating) identities of social actors, individual or corporate, gradually emerge from the multiple roles these actors actively perform in their particular networks (which inherently contain social dynamics and are the essential sites of co-evolutionary meaning-formation). That is why the social researcher's analytic framework must now strategically move from the traditional atomistic "focus on the individual to a relational analysis" (Morris 2004, 2). The person then ceases to be the fundamental, unquestioned and unproblematised elementary building block of social analysis (White 1992, 197). In general, the main proponents of relational sociology (Harrison White, Mark Granovetter, Peter Bearman, Paul DiMaggio, Charles Tilly, Roger Gould, and Ann Mische) rejected the obsolete structuralism of network analysis and proceeded to variously model social structures neither as patterns between individuals (in the tradition of Radcliffe-Brown and Nagel) nor as meaningless entities, but as meaningful dynamic networks. 
This pertains to an ongoing cultural process of re-constructing fluid identities, associations and linkages that transcend older ties of place, time, gender, class, race, ethnicity, and so on. In this sense, "networks", as complex emergent structures of interconnection between actors (see Figure 1), do not merely reflect the social structure but rather re-shape and even re-create society (Urry 2000). Importantly, social networks involve all levels of our stratified reality and affect both individual success or failure and the development of large-scale social phenomena, such as social movements and protests, markets, academic communities or political regimes (Fuhse 2015, 1).

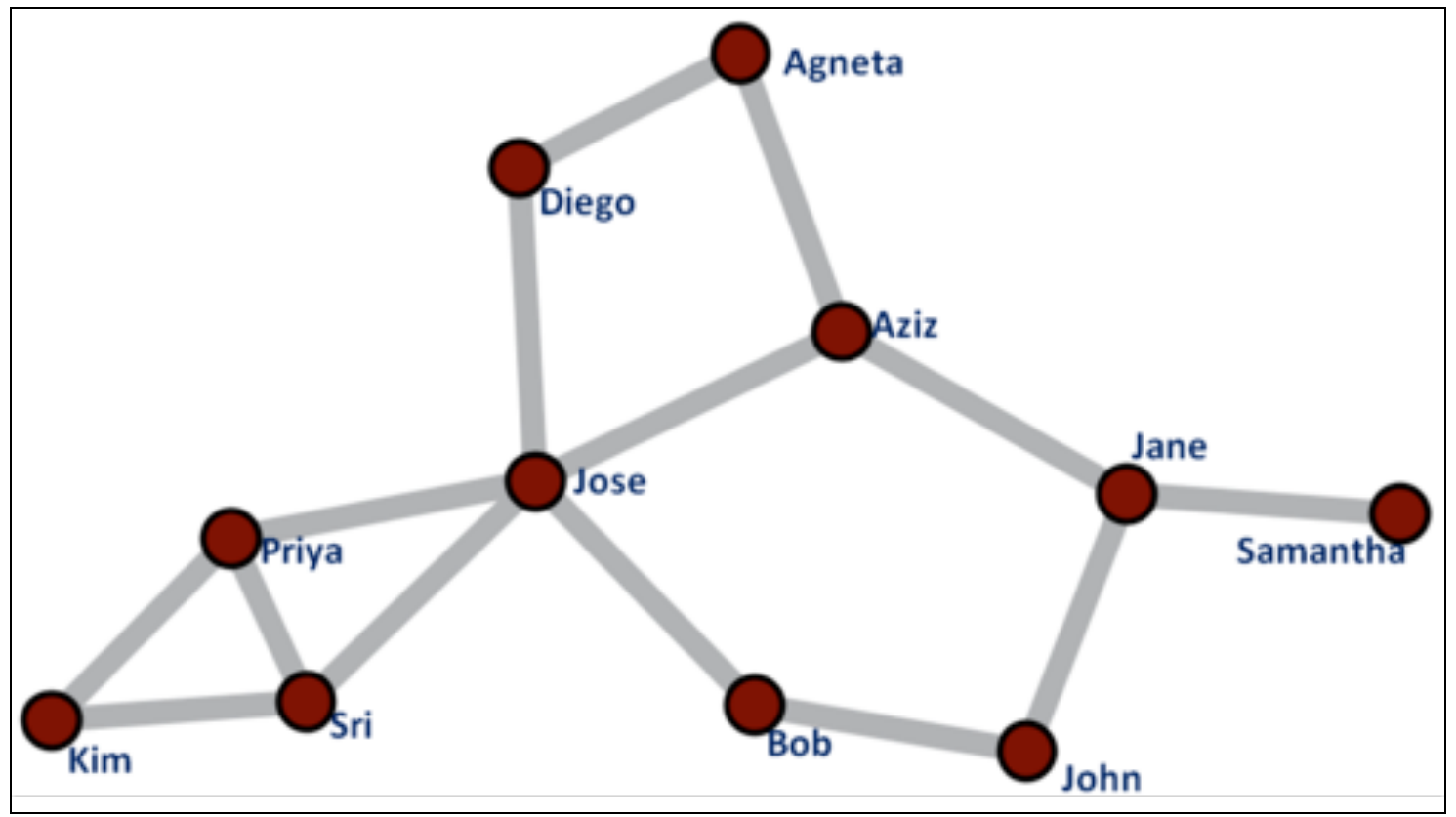

Figure 1: A picture is worth a thousand words: A small social network depicting individual human agents and their relationship pattern.

Source: https://en.wikipedia.org/wiki/Katz centrality. CC attribution: "A simple social network: the nodes represent people or actors and the edges between nodes represent some relationship between actors" by ADuvvuru, licensed under CC BY 3.0

\section{Two Sociologies of Networks}

We therefore set out from the fundamental assumption that sociology must study communicative interactions and social relationships between individuals, rather than isolated facts or individual attributes and personality characteristics. ${ }^{4}$ In general, the sociology of networks sees networks as complex socio-cultural formations ${ }^{5}$ and as uncertain results of collective action (and less as a precondition), and focuses on meaningful communication, interdependence, unplanned order, mobilities, flows and relations, transcending the old dualistic dichotomies between action and structure, individual and society, micro and macro, or local and global, as well as the various analytic attempts to distinguish between them (Dépelteau and Powell 2011; Fuhse

${ }^{4}$ Although he never directly used the phrase "social networks" in his writings, Georg Simmel (1950, 22) systematically focused on how social communicative interactions are influenced by the multiple ways in which people get connected to one another, and argued that the societal forms "are conceived as constituting society (and societies) out of the mere sum of living men. The study of this second area may be called 'pure sociology', which abstracts the mere element of sociation".

${ }^{5}$ To use Jan Fuhse's words, all social networks are "intersubjective constructs of expectations and cultural forms" (Fuhse 2009, 52). 
2015). It is arguable to assume that there is a profound tension between the critical and the normative-functionalist sociology of networks (Martinez 2007). ${ }^{6}$ Yet, the current sociological literature (especially the methodological part) seems to emphasise on the latter one.

According to the normative-functionalist approach to social networks, the actions and interactions of individuals or "network agents" are more or less dictated by belief system, institutional norms, rules and obligations (Coleman 1988). Adherence to such norms has moral importance and is a key to success and social recognition. On the contrary, a critical network approach turns the focus of our analytic attention upon the strong tensions, contradictions and disparities in social capital between the dominant and minority social groups or classes, identifying the hidden influences or causal effects of structural factors, such as socioeconomic status, social inequalities, ethnicity, and gender (Martinez 2007).

This approach is somewhat evident in Pierre Bourdieu's (1977) critical theorisation the field of education as a relational network of class-based social positions. That is, the educational system (as a whole) serves as a powerful mechanism that helps to maintain and perpetuate the status quo, as well as to reproduce and legitimate existing social patterns and inequalities, as higher-class individuals (and elites) are seen to "naturally" deserve their place in the social hierarchical structure. For instance:

By doing away with giving explicitly to everyone what it implicitly demands of everyone, the education system demands of everyone alike that they have what it does not give. This consists mainly of linguistic and cultural competence and that relationship of familiarity with culture which can only be produced by family upbringing when it transmits the dominant culture. (Bourdieu 1977, 494)

A critical network analytic framework thus poses urgent questions on the stratified nature of social capital (Stanton-Salazar 2011), as well as on the complex links between social capital and dominant societal values and attitudes, underlying multiple issues of conflict, ideology and power relations (beyond the mere focus on institutional and interpersonal trust). As Norbert Elias rightly observes: "Power is not an amulet possessed by one person and not by another; it is a structural characteristic of human relationships_of all human relationships" (Elias 1978, 75). In this regard, decontextualising the crucial dimension of cultural, racial and socioeconomic status (including the common practices of exclusion and discrimination) from the discussion of social capital and access to resources, as James Coleman (1988) does, offers an inadequate account of social capital processes.

Additionally, the need to address inequalities of economic power, political power and cultural power (reputation) that shape (and are shaped by) social relations moves the center of our critical analysis to local network interactions, which give rise to hegemonic discourses and in turn guide collective action and societal change. We must then discern and transform potentially negative interactions into mutually beneficial cooperation and collective intelligence (Helbing 2016). What is also evidenced in terms of network power is that network structure matters (Borgatti and Halgin

${ }^{6}$ Another possible tension is pointed out by Stephen Borgatti and Virginie Lopez-Kidwell (2011), who analytically distinguish "between two ways of network theorizing: 'theories of networks' focus on tie formation, treating networks as the dependent variable; and 'network theory' deals with effects of networks, treating them as an independent variable" (Fuhse $2015,14)$ 
2011) and influences who the hubs in a communication/social network are and what resources they control.

\section{Social Network Analysis}

Furthermore, Nicholas Christakis and James Fowler (2009) use social network anal$y \operatorname{sis}^{7}$ to determine how associations (e.g. proximity, mating, grooming) within social groups affect a person's health, physical activity, tastes, mood, happiness, wellbeing, and so on. But they do not efficiently elaborate on symbolic power and the differential access to social networks and social resources, albeit their profound analytic emphasis on the holistic (top-down) influence and dynamics of large, fluid social groupings. In addition, critical agency, identities and the meaning of action are seen as the outcome of supra-personal transactional processes in the communicative networks. By exclusively focusing on the effects of networks (treating them as an independent variable), "network theory" also downplays the bottom-up (agent-based) dynamics of individual personality, creativity, improvisation, imagination and emotions. ${ }^{8}$

In this network approach, the "size" of the nodes (knowledgeable actors with bounded reflexivity) depends on the value of their "degree centrality" (number of connections). In general, centrality pertains to someone's structural position in the network, that is, near center vs. near edge, reflecting the extent to which an agent's contacts are well-connected to others. The centrality measures are essential metrics to understand and analyse the position of an actor in a network. They come in many variations, as shown in Figure 2.

\footnotetext{
${ }^{7}$ Social Network Analysis (SNA) offers a set of tools to empirically extend our theoretical intuition of social connectivity and of the relational patterns that construct social structure. It is noteworthy to mention that Social Network Analysis is a parallel field to Network Science in that "there is very little overlap between researchers in the respective fields despite the similiarity of the problems. Whereas solutions to problems in social networks have tended to be data-oriented in that models and statistical tests are based on the data, those in network science have tended to be phenomenon-oriented with analogies to problems in the physical sciences often providing the backbone for solutions. Methods for social network analysis often have causal hypotheses (e.g. does one individual have an effect on another, does the presence of a common friend make friendship formation more likely) motivating them and involving micro-level modeling. In contrast, methods in network science seek models generated from some theoretical basis that reproduce the network at a global or system level and in so-doing reveal features of the data generating process (e.g. is the network scale-free, does the degree-distribution follow a power-law)" (O'Malley and Onnela 2014, 2).

${ }^{8}$ Since the mid 1990s, social network analysis has been rapidly maturing as an interdisciplinary or transdisciplinary scientific research field, with the publication of many handbooks and edited volumes, and the development of new advanced software packages. But it is often accused of seriously lacking specific analytic attention to complex intersubjective processes of symbolic interpretation and meaning-construction. For instance, Arthur Stinchcombe strongly criticises social network analysis as follows: "One has to build a dynamic and causal theory of a structure into the analysis of links [...] We need to know what flows across the links, who decides on those flows in the light of what interests, and what collective or corporate action flows from the organization of links, in order to make sense of intercorporate relations" (Stinchcombe 1990, 381).
} 


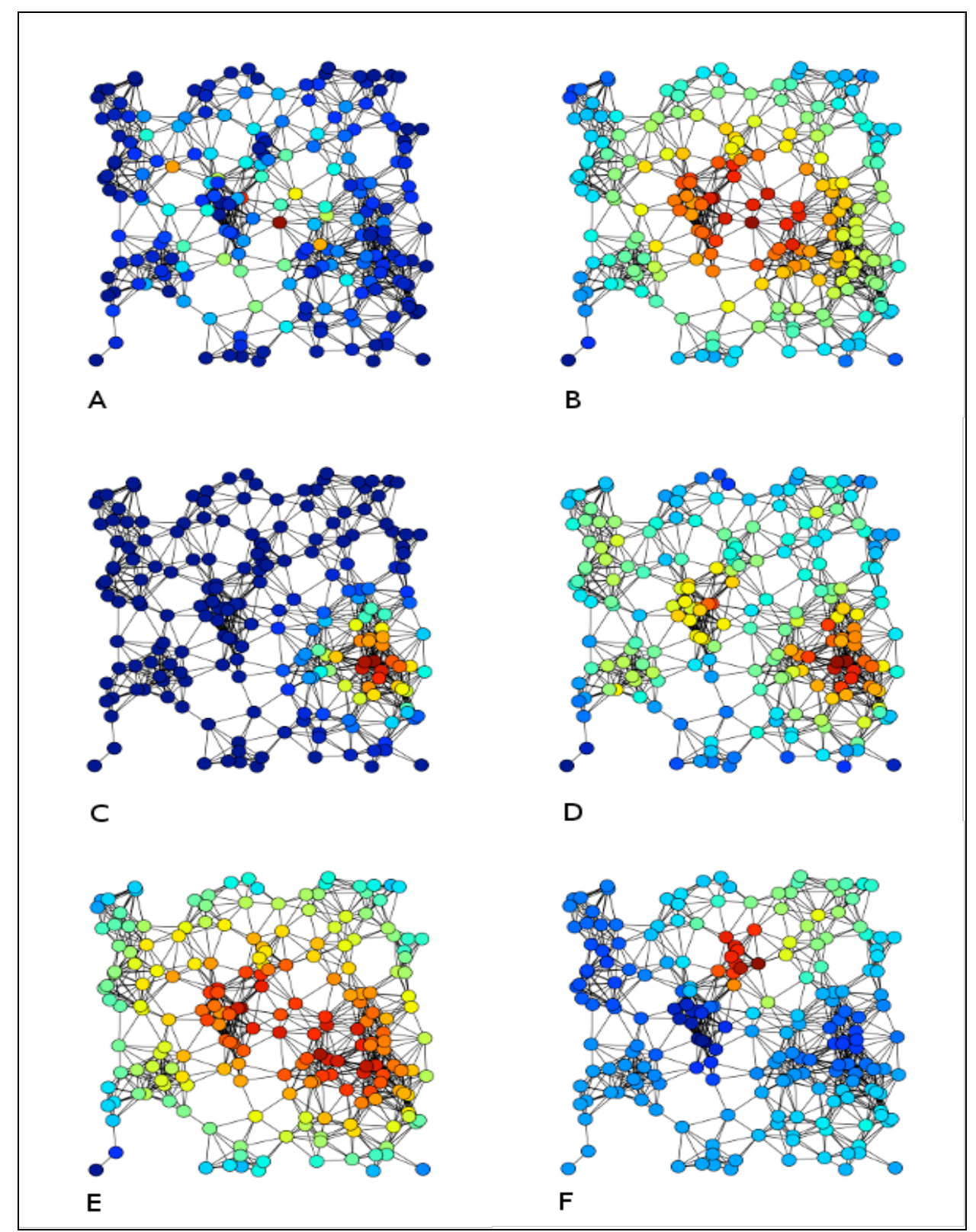

Figure 2: Variations in centrality measures.

Source: https://en.wikipedia.org/wiki/Centrality. CC attribution: "Examples of A) Betweenness centrality, B) Closeness centrality, C) Eigenvector centrality, D) Degree centrality, E) Harmonic centrality and

F) Katz centrality of the same graph" by Tapiocozzo, licensed under CC BY-SA 4.0

Although network location is indeed important, the critical analytic attention on the way reflexive identity processes operate to structure social institutions and exchanges should not be undermined. Traditionally, mathematical sociologists and social network analysts (inspired from matrix algebra and graph theory) formalise the social structure, draw on the foundations of the realist epistemology, and aim to dismiss normative explanations of social behaviour in favour of an "objective" analysis of the social distribution of possibilities (Wellman 1983). ${ }^{9}$

9 Nowadays, sophisticated computer programs provide both descriptive and analytical accounts in terms of the patterns and configurations of ties. These programs offer pictures (visualisations) of the social networks being studied, as well as the matrix of connections and calculations representing the patterns and configurations of ties, so that "objectively meas- 
Yet, over against objectivist, technicist, or positivist concerns, a critical sociology of networks should bring people in the centre of a relational theory of society, as Norbert Elias (1991) perceptively did it. It is the people who act and societies are powerladen communicative networks (dynamic figurations) ${ }^{10}$ of human beings, not disembodied actions or "actants" or "heterogeneous materials", pertaining to the vague processual "work of translation" or "mediation", which somehow results in the spontaneous creation of sociotechnical objects, "hybrids" and "collectives" (Latour 2005; Mol and Law 1994; Law 1992).

We thus have to argue in favour of a new, radical network theory that "clearly locates itself in the humanities and cultural studies rather than faking scientific formalisms, simulating scientific interdisciplinarity and ultimately ending up as history of science and technology [...] A new network theory therefore needs to be a critical network theory, be built on the insight that networks - and the Internet - are neither good or bad per se, nor universal models and descriptors of culture" (Cramer 2007). ${ }^{11}$

\section{Networks and Critical Awareness}

Moreover, when focusing too much on tie formation and nodal interactions (treating networks as a dependent variable), "theories of networks" overestimate obvious and empirically observable interactive relationships. Hence, they tend to overlook the theoretically deductible relationships in the social fields (Bourdieu) or social configurations (Elias). Human "agents" do not act and interact in a social vacuum (rationally drawing on an unlimited reflexive capacity and instrumentally reflecting on the best ways, tools or techniques to achieve unquestioned goals) and do not "freely" shape their social communicative networks. These networks can be seen as a causal factor forming social dynamics. In other words, they involve causal inference and not "just methodology" or "mere description" (Borgatti et al. 2009).

Individuals construct their personal and social networks and, concurrently, they are constructed by those networks: "Many networks are the product of dynamical processes that add or remove vertices or edges. For instance, a social network of friendships changes as individuals make and break ties with others. [...] The ties people make affect the form of the network, and the form of the network affects the

ured social connections allows us to avoid qualitative evaluations that lead to subjective, and possibly biased, understanding of specific social phenomena" (Eisenberg and Houser 2007). By setting up the normative goal of a critical network theory, of course, does not imply a complete rejection of networks as templates for organising sociality but rather to reflect upon the limits of networks as models for organising the social (Mejias 2010).

${ }^{10}$ Social figurations, as networks of relations between people, are never static; they are always in a state of structured flux (or deterministic flux) and their "dynamics can be seen in the longer and shorter term and might include state formation processes, civilizing and decivilizing processes, or the deamateurization of sport amongst many others" (Liston and Mennell 2007).

${ }^{11}$ For Florian Cramer (2007), a new network theory should radically take apart from a long series of false identifications: "Feedback is not interaction, computation is not cognition, storage is not memory, data is not knowledge, telecommunication switches are not social networking. The cybernetic mapping is not the cultural territory". Hence, it would effectively avoid the trap of conflating phenomena that any critical theory must rather differentiate: "telecommunication switches from social networking, machine feedback from human interaction, computation from cognition, storage from memory, data from knowledge, syntax from semantics, and so on" (Cramer 2007). 
ties people make. Social network structure therefore evolves in a historically dependent manner, in which the role of the participants and the patterns of behavior they follow cannot be ignored" (Newman et al. 2006, 7). Therefore, social theorists and researchers ought to maintain a critical explanatory view on the ongoing dialectic of bottom-up and top-down emergence in contemporary complex social systems (Fuchs and Hofkirchner 2005).

Besides, network power is naturalised by language (and ideology) and human agency is always relationally mediated by symbolic backgrounds, internalised semiotic processes or embodied knowledge (like Bourdieu's Habitus ${ }^{12}$ ), which function in between cognition and society (Koegler 2012). As Hans-Herbert Koegler sophisticatedly puts it, "human selves mutually relate to one another's beliefs and assumptions within a context constituted by a shared background of assumptions and practices. Linguistic communication consists of agents producing explicit statements based on this backdrop, which are addressed to one another by recognizing the involved agents as expressive-reflexive subjects of a common understanding vis-à-vis a subject matter" (Koegler 2012, 53). Communication also involves the ongoing silent workings of the social unconscious, that is, invisible and unreflective processes, which include power relationships, social conventions and cultural norms, determining how one experiences and evaluates their networked self, their networked world, and the emergent relationships (networks) between or around them as "natural" (Dalal 2001, 2004). ${ }^{13}$

Most importantly, a critical sociology of networks and relations (like any critical sociology) must presuppose "not only an analysis of the forces of social domination, but also an analysis of the social forces of emancipation and the possibility of a transformative politics of emancipation", as well as "an ethics, or at least some formulation of normative criteria of moral judgement and some indication of the "good life"' (Vandenberghe 1999, 62). That is, we need a critique of pure reason, a critique of judgement, and a critique of practical reason. The latter entails seeing things otherwise, as well as creating and expanding new possibility spaces for critical agency albeit its (inescapable) network embededness. ${ }^{14}$

\footnotetext{
12 That is, the practical sense of the game and of the position occupied by the social agent (Bourdieu 1977).

${ }^{13}$ For Farhad Dalal (2004), all group processes (or social processes) are essentially power processes. He thus criticises the founding father of group analysis, S.H. Foulkes, for keeping his group analytic model "clean" by the use of "scientific terms" like nodes and networks. Although Foulkes maintains time and time again that the individual is permeated to the core by the social, he does not adequately manage to take the leap himself into the truly social. In this line of analysis, Foulkes remains "in a pseudo-scientific frame to say that the individual is a node in a network of communication, or sometimes he says that the individual resides in a field of communications. These terms (node, network, field) are drawn from physics, and so his analogy lends itself to be thought of as something objective; i.e. as a description of fact that is not influenced by the vagaries of social convention" (Dalal 2004, 7). Dalal uses here the term "'pseudo-scientific"' because "the notions of network, node and so forth are ultimately metaphors and analogies" (Dalal 2004, 20, n.2). See also Eran Fisher's (2010) conception of networks as ideology. According to "the new spirit of networks", Web 2.0 platforms are serving neoliberal interests and legitimating capitalism (Fisher 2010).

14 The concept of embededness means that, "[...] action is always socially situated and cannot be explained by reference to individual motives alone, and that socials institutions do not arise automatically in some inevitable form but rather are socially constructed" (Granovetter 1990, 95-96).
} 


\title{
5. Networks and Data in Digital Society
}

The analytical concern on critical human agency is crucial in theorising our increasingly globalised, reflexive and information-saturated "hypernetworked world" ${ }^{15}$ which is seriously threatened by digital divide, exploitation of digital labour, corporate dominance, ownership, and control over large parts of the media and communication technology, infrastructure and content (let alone cybercrime, data theft or fraud, systematic large-scale surveillance and massive manipulation of Internet users). ${ }^{16}$ This calls for new forms of policy and regulation, heavily informed by critical network thinking and complexity science (Helbing 2015), able to affect Internet access and content, as well as to promote collective intelligence, sharing, collaboration, diversity, pluralism and the deconcentration of power, running the Internet of Things as a participatory Citizen Web. ${ }^{17}$

Furthermore, much sociological research to date has focused on various aspects of online social networking, such as online relationships and online-offline connections, friendship and intimate relationships, profiles and self-presentation, privacy and surveillance, anonymity and trust, and so on. But since such research tends to locate the actor at quite different levels, suggesting a conceptual separation between individual-oriented and system-oriented agency, we should rather prefer the term "social intermediaries"-instead of "SNS" (Berg 2012). This arguably provides a reflexive way to re-conceptualise SNS with respect to their functional position in the social, thus offering an important alternative to contemporary instrumental and institutional accounts (Berg 2012, 12):

\begin{abstract}
social intermediaries should not only be regarded as sites and applications that provide a means for individual pursuits or function as instruments for harvesting personal information but rather as distinct and somewhat independent entities. Understood in this way, social intermediaries enter the social situation as a third actor, while at the same time providing the infrastructural condition for that very situation [...] In this sense, such a conceptualisation of social intermediaries provides an opportunity to shift focus towards the social realm as such, which facilitates the establishment of an understanding that can be critically related to a larger theoretical whole.
\end{abstract}

15 Online networks, like other contemporary techno-social systems, consist of "large scale physical infrastructures [...] embedded in a dense web of communication and computing infrastructures whose dynamics and evolution are defined and driven by human behaviour" (Vespignani 2009: 425). The multiscale nature, diversity and complexity of these networks are crucial features in better understanding them. Both methodological and epistemological advances in complex online networks are providing an integrated framework, without however achieving true predictive power of their behaviour. This particularly indicates that chaos, unpredictability, non-linearity and indeterminacy, as significant constitutive features of the emergent virtual worlds, should always be placed at the centre of the critical analysis (Tsekeris and Katerelos 2012).

${ }^{16}$ In some sense, the surprising proliferation of digital networks in the 21 st century has demonstrated the highly ambivalent and contradictory potentials of technological development. What is substantially required is to mobilise their empowering qualities through an effective critique of corporate dominance. This also urges for new critical developments in sociological perspectives and imagination.

${ }^{17}$ Nowadays, as Dirk Helbing (2015) describes, a wide range of previously offline devices (such as TV sets, fridges, coffee machines, toothbrushes, and cameras), smart wearable devices (such as activity trackers) and measurement sensors are connected to the Internet, creating the "Internet of Things" (loT) or "Internet of Everything" (loE). Soon there will be more networked machines than human users in the Internet. This provokes a huge explosion in data volumes and calls for entirely new paradigms for running our smart networked (algorithmic) societies. In the last instance, the Internet of Things, with its vast underlying networks of sensors, can arguably make socioeconomic self-organization possible in a distributed and bottom-up way. The crucial question on how to make a data-oriented approach based on distributed control work rather requires a critical complexity science (Helbing 2015). 
Critical network thinking is also aimed by Manuel Castells who puts a very strong emphasis on the mobilisation capacities of the Internet: "The Internet provided the safe space where networks of outrage and hope connected. Networks formed in cyberspace extended their reach to urban space" (Castells 2012: 81). Online social networks "allowed the experience to be communicated and amplified, bringing the entire world into the movement" (Castells 2012: 169). Although, in his Networks of Outrage and Hope, Castells (2012) obviously overestimates the role of the Internet in society and downplays or neglects the irreducible multidimensionality of society and its broader relational context (see Fuchs 2012), thus fetishising or naturalising digital networks, instead of being critical against them. Changing the world nowadays requires among many things a genuinely critical and anti-reificatory understanding of technological networks (of any kind).

Besides, critical sociological thinking, as advanced by Max Horkheimer, Theodor Adorno and Herbert Marcuse, who were heavily inspired by the Marxist concept of emancipation, urges us to create proper analytical frameworks that will help people to see and get rid of hidden structures of oppression and exploitation, as well as to realise that economic relations are emergent products of human work (Ingram and Simon-Ingram 1992). Hence, a critical sociology of networks should overtly oppose to any version of naturalism, instrumentalism and technological determinism, with the aim to reconceptualise (1) society as a total relational system and (2) communication infrastructures and networks as relationally influenced by the political organisation of economy (political economy).

Of course, online social networks have so far enabled many de-centralised political activities challenging top-down state control and domination. They played an active role in the Arab Spring, the mass popular insurrections in Turkey, the grassroots protest movement of Los Indignados (the "Outraged") in Spain and Portugal, the protest movement Occupy Wall Street in USA, and the so-called "square" movement of Aganaktismenoi in Greece, also known as the Indignant Citizens Movement (let alone the huge contribution of blogs to the social upheavals and the Jasmine Revolution in Tunisia, resulting in the collapse of Ben Ali's government, as well as to antiauthoritarian and anti-poverty popular movements throughout the Arab world such as Libya, Egypt, Syria, Iran, Yemen, Algeria, Morocco, Jordan, Bahrain, Syria, Kuwait, etc). ${ }^{18}$

However, up-to-date experience implies that the "democratising effects" of social networking platforms (like Twitter) may also reduce the level of critical public discussion, rather than substantially elevating it, as well as absorb "the accuracy that comes from reliance on experts" (Tenopir 2007, 36). Ignorant mob attitudes and misinformation never go away, so that "our collected information becomes infected by mistakes and fraud" (Keen 2007, 65). We therefore need to permanently provoke and challenge Web 2.0's ideological embedment and false claims, often reinforced by powerful commercial interests, states, and professional elites (Scholz 2008). In the same critical line of thought, Vincent $\operatorname{Mosco}(2014,28)$ perceptively argues against repeated pro-innovation biases and hyper-optimistic accounts, emphasising that we should do "more than marvel at the advance in technology over the decades, because history suggests that technological progress does not necessarily bring about advances in the practice of democracy, and sometimes can result in genuine regression".

\footnotetext{
${ }^{18}$ For a relevant discussion, see Boikos et al. 2014. Nevertheless, we do need a true social media revolution that makes "social media" truly and fully social (Fuchs 2014).
} 
Last but not least, a critical sociology of networks must apprehend and interrogate the nature, character and dynamics of the data produced within the myriad interconnected networks around us. On the one hand, the social is being re-fabricated and re-configured through ubiquitous data-driven processes. According to David Beer and Roger Burrows $(2013,63)$, "the 'stuff' that makes up the social fabric has changed ... social associations and interactions are now not only mediated by software and code but they are also becoming increasingly constituted by it". ${ }^{19}$ One the other hand, power is being made more and more invisible and taken-for-granted by the increased presence of complex digital data systems throughout society (Lupton 2014)..$^{20}$

This entails a critical data science aiming to discover and uncover power effects and exploitative relationships of any kind (Kitchin 2014). For instance, Nikos Askitas utilises Google analytics (big data heuristics) to detect and highlight the profound relationship between right radicalism in contemporary Germany, that is, the case of the Alternative for Germany (AfD) party which rises in eastern Saxony, and the decrease of income level (after the latest expressions of hostility towards foreigners and refugees) (see Figure 3). ${ }^{21}$

${ }^{19}$ In addition, "the processes involved in naming, structuring and processing data [...] are profoundly social with tremendous sociological implications" (Halford et al. 2013, 180).

${ }_{20}$ Vincent Mosco (2014) rightly warns us against highly powerful data politics and digital positivism (data processes of meaning-making are never innocent, neutral and objective), as well as against the systemic practice to assess patterns in society as the ultimate goal of Big Data, since it "is increasingly used to analyze, model, and forecast human behaviour" (Mosco 2014, 182).

${ }^{21}$ This also offers a vivid empirical demonstration of the fact that " 25 years after the German reunification and after billions of solidarity taxes paid, the East is still far behind the West not just in terms of income but also in terms of tolerance and cultural pluralism" (Askitas 2016). 


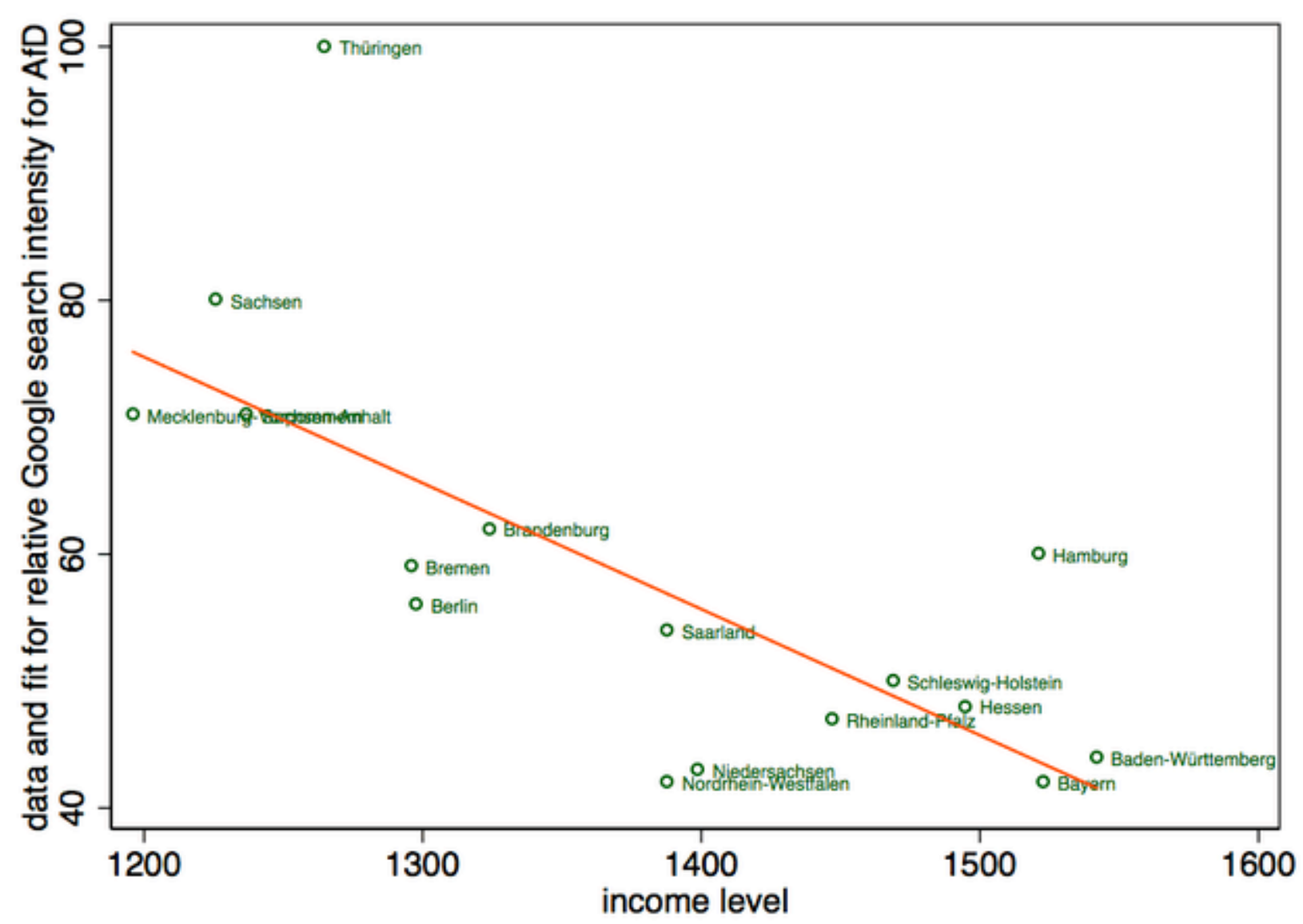

Figure 3: A scatter plot of income level by land and Google search intensity for AfD, showing that bad economic conditions breed right radicalism, as well as that the proliferation of $\mathrm{AfD}$ in the east will most likely make things worse.

Source: www.askitas.com/2016/02/23/the-german-east-west-divide-in-light-of-the-events-in-saxony/ (Courtesy of Nikos Askitas, Institute for the Study of Labor, Germany)

Rather than "just following" the data and data scientists, we need a critical reflexive awareness of the complex forms of knowledge being produced, as well as of our own role in that process. Furthermore, doing critical work with Big Data "involves understanding not only data's formal characteristics, but also the social context of the research amidst shifting technologies and broad social processes. Done right, 'big' and small data utilized in concert opens new possibilities: topics, methods, concepts, and meanings for what can be understood and done through research" (Dalton and Thatcher 2016).

\section{Concluding Remarks}

Nevertheless, we still need to find new concepts, research methods, frameworks and radical alternatives (Fuchs 2014, 2015) that can be placed in the service of generating a more critical understanding of complex social networks ${ }^{22}$ and their potential to contribute to progressive social change within contemporary communicative capital-

\footnotetext{
${ }^{22}$ Such critical understanding pertains not only to how power works, but also to what it means to be human and to have a human society.
} 
ism. In addition, we must continue to challenge emerging power inequalities and remain critical of what we may find.

Meaningful networks of any kind are behind complex systems (which are located on the boundary or edge between order and chaos) and capture the intricate web of connections (or clusters) among their constituent units. This web has non-trivial correlations and specific scaling properties (Palla et al. 2005). Network organisation must however be interpreted not only in terms of the coexistence of their structural subunits (communities) associated with more highly interconnected parts, but also in critical theoretical terms. Having a critical grasp of both the universal and specific (essential) features of the networks associated with huge sets of data (Big Data), which are accumulating at a tremendous pace in various fields of human activity, has become a very significant task.

Living in a multiplicity of social networks entails an ongoing playful interdependency that profoundly provides us with the very possibility of human communication, cooperation, creativity, dialogue, synthesis and critique. A critical sociology of networks openly recognises, acknowledges and celebrates interconnectivity, emergence and change, so that we can become active co-participants and co-creators rather than passive subjects or arrogant masters of our nonlinear relational world. This conflictridden world contains undecidable mixes of love and hate, empathy and power (Dalal 2004, 18):

\begin{abstract}
Humans are not only always in social networks and so constitute them, it is also the case that they are simultaneously formed at the deepest of levels by the vicissitudes these networks. We continually influence and are influenced by each other-and this is not a matter of choice, or something one can 'rise' above. We are empathy machines, 'designed' by the processes of natural selection to relate to other human beings. Where one will be drawn to love or to hate will be dependent on where one is positioned by the multitude of contesting and intersecting discourses and ideologies-in other words by power relations as they drive the vicissitudes of the social contexts that we inhabit.
\end{abstract}

\title{
References
}

Askitas, Nikos. 2016. The German East-West Divide in Light of the Events in Saxony. Signals in the Noise. http://www.askitas.com/2016/02/23/the-german-east-west-divide-inlight-of-the-events-in-saxony/.

Barnes, John. 1969. Graph Theory and Social Networks: A Technical Comment on Connectedness and Connectivity. Sociology 3 (2): 215-232.

Beer, David and Roger Burrows. 2013. Popular Culture, Digital Archives and the New Social Life of Data. Theory, Culture \& Society 30 (4): 47-71.

Berg, Martin. 2012. Social Intermediaries and the Location of Agency: A Conceptual Reconfiguration of Social Network Sites. Contemporary Social Science. http://urn.kb.se/resolve?urn=urn:nbn:se:hh:diva-17450.

Boikos, Christos, Konstantinos Moutsoulas and Charalambos Tsekeris. 2014. The Real of the Virtual: Critical Reflections on Web 2.0. tripleC: Communication, Capitalism \& Critique 12 (1): 405-412. http://www.triple-c.at/index.php/tripleC/article/view/566/642.

Borgatti, Stephen and Daniel Halgin. 2011. On Network Theory. Organization Science 22 (5): 1168-1181.

Borgatti, Stephen, Ajay Mehra, Daniel Brass, and Giuseppe Labianca. 2009. Network Analysis in the Social Sciences. Science 323 (5916): 892-895.

Borgatti, Stephen and Virginie Lopez-Kidwell. 2011. Network theory. In Sage Handbook of Social Network Analysis, eds. John Scott and Peter Carrington. Thousands Oaks: Sage.

Bourdieu, Pierre. 1977. Cultural Reproduction and Social Reproduction. In Power and Ideology in Education, eds. Jerome Karabel and Albert Halsey. Oxford: Oxford University Press. 
Castells, Manuel. 1996. The Rise of the Network Society. The Information Age: Economy, Society and Culture, Vol. I. Oxford: Blackwell.

Castells, Manuel. 2012. Networks of Outrage and Hope. Social Movements in the Internet age. Cambridge: Polity Press.

Christakis, Nicholas and James Fowler. 2009. Connected: The Surprising Power of our Social Networks and how they Shape our Lives. New York: Little Brown.

Coleman, James. 1988. Social Capital in the Creation of Human Capital. American Journal of Sociology 94 (S): 95-120.

Cramer, Florian. 2007. "Text" and "Network", Reconsidered. Institute of Network Cultures. www.networkcultures.org/networktheory/resources/\#florian.

Crossley, Nick. 2015. Relational Sociology and Culture: a Preliminary Framework. International Review of Sociology 25 (1): 65-85.

Dalal, Farhad. 2001. The Social Unconscious: A Post-Foulkesian Perspective. Group Analysis 34 (4): 539-555.

Dalal, Farhad. 2004. Power, Shame and Belonging: Radical Group Analytic Theory. Unpublished work.

Dalton, Craig and Jim Thatcher. 2014. What Does a Critical Data Studies Look Like, and Why Do We Care? Seven Points for a Critical Approach to 'Big Data'. Society and Space. www.societyandspace.com/material/commentaries/craig-dalton-and-jim-thatcher-whatdoes-a-critical-data-studies-look-like-and-why-do-we-care-seven-points-for-a-criticalapproach-to-big-datal.

Dépelteau, François and Christopher Powell. 2011. Applying Relational Sociology. New York: Palgrave Macmillan.

Eisenberg, Anne and Jeffrey Houser. 2007. Social Network Theory. In Blackwell Encyclopedia of Sociology, ed. George Ritzer. Blackwell Reference Online. http://www.sociologyencyclopedia.com/subscriber/tocnode.html?id=g9781405124331_yr2 012 chunk g978140512433125_ss1-171.

Elias, Norbert. 1978. What is Sociology? New York: Columbia University Press.

Elias, Norbert. 1991. The Society of Individuals. Oxford: Basil Blackwell.

Erikson, Emily. 2013. Formalist and Relationalist Theory in Social Network Analysis. Sociological Theory 31 (3): 219-242.

Fisher, Eran. 2010. Media and New Capitalism in the Digital Age. The Spirit of Networks. New York: Palgrave Macmillan.

Fuchs, Christian. 2014. Social Media: A Critical Introduction. London: Sage.

Fuchs, Christian. 2015. Culture and economy in the Age of Social Media. New York: Routledge.

Fuchs, Christian and Wolfgang Hofkirchner. 2005. The Dialectic of Bottom-up and Top-down Emergence in Social Systems. tripleC: Communication, Capitalism \& Critique 3 (2): 2850. http://www.triple-c.at/index.php/tripleC/article/view/21/20.

Fuhse, Jan. 2009. The Meaning Structure of Social Networks. Sociological Theory 27 (1): 51-73.

Fuhse, Jan. 2015. Theorizing Social Networks: the Relational Sociology of and around Harrison White. International Review of Sociology 25 (1): 15-44.

Granovetter, Mark. 1990. The Old and the New Economic Sociology: A History and an Agenda. In Beyond the marketplace: Rethinking economy and society, eds. Roger Friedland and Alexander Robertson. New York: Aldine de Gruyter.

Halford, Susan, Catherine Pope and Mark Weal. 2013. Digital Futures? Sociological Challenges and Opportunities in the Emergent Semantic Web. Sociology 47 (1): 173-189.

Helbing, Dirk. 2015. The Automation of Society is Next: How to Survive the Digital Revolution. Available at SSRN: http://ssrn.com/abstract=2694312.

Ingram, David and Julia Simon-Ingram. 1992. Critical Theory: The Essential Readings. St. Paul, MN: Paragon House.

Keen, Andrew. 2007. Cult of the Amateur. New York: Doubleday. 
Kitchin, Rob. 2014. Short Presentation on the Need for Critical Data Studies. The Programmable City blog. http://www.nuim.ie/progcity/2014/04/short-presentation-on-the-need-forcritical-data-studies/.

Koegler, Hans-Herbert. 2012. Agency and the Other: On the intersubjective roots of selfidentity. New Ideas in Psychology 30 (1): 47-64.

Latour, Bruno. 2005. Reassembling the Social: An Introduction to Actor-Network-Theory. Oxford: Oxford University Press.

Law, John. 1992. Notes on the Theory of Actor-Network: Ordering, Strategy and Heterogeneity. Systems Practice 5 (4): 379-393.

Liston, Katie and Stephen Mennell. 2007. Figurational Sociology. In Blackwell Encyclopedia of Sociology, ed. George Ritzer. Blackwell Reference Online.

http://www.sociologyencyclopedia.com/subscriber/tocnode.html?id=g9781405124331_yr2 012 chunk g978140512433112 ss1-81.

Lupton, Deborah. 2014. Digital Sociology. London: Routledge.

Martínez, David Angel. 2007. The Manifestation of Social Capital within the Mathematics, Engineering, and Science Achievement (MESA) Program. PhD Thesis, Rossier School of Education, University of Southern California.

Mejias, Ulises. 2010. The Limits of Networks as Models for Organizing the Social. New Media \& Society 12 (4): 603-617.

Mol, Annmarie and Law, John. 1994. Regions, Networks and Fluids: Anaemia and Social Topology. Social Studies of Science 24 (4): 641-671.

Moreno, Jacob. 1961. The role concept, a bridge between psychiatry and sociology. American Journal of Psychiatry 118 (6): 518-523.

Morris, Martina. 2004. Editor's Introduction. In Network Epidemiology: A Handbook for Survey Design and Data Collection, ed. Martina Morris. Oxford and New York: Oxford University Press.

Mosco, Vincent. 2015. To the Cloud: Big Data in a Turbulent World. Boulder, CA: Paradigm Books.

Newman, Mark, Albert-László Barabási and Duncan Watts. 2006. The Structure and Dynamics of Networks. USA: Princeton University Press.

O'Malley, James and Jukka-Pekka Onnela. 2014. Topics in Social Network Analysis and Network Science. arXiv preprint arXiv:1404.0067.

Palla, Gergely, Imre Derényi, Illés Farkas and Tamás Vicsek. 2005. Uncovering the Overlapping Community Structure of Complex Networks in Nature and Society. Nature 435 (7043): 814-818.

Rainie, Lee and Barry Wellman. 2012. Networked: The New Social Operating System. Cambridge, MA: MIT Press.

Scholz, Trebor. 2008. Market Ideology and the Myths of Web 2.0. First Monday 13 (3). www.firstmonday.org/htbin/cgiwrap/bin/ojs/index.php/fm/article/view/2138/1945.

Simmel, Georg. 1950. The Sociology of Georg Simmel (ed. K. H. Wolff). New York: Free Press.

Stanton-Salazar, Ricardo. 2011. A Social Capital Framework for the Study of Institutional Agents and their Role in the Empowerment of Low-Status Students and Youth. Youth \& Society 43 (3): 1066-1109.

Stinchcombe, Arthur. 1990. Weak Structural Data. Contemporary Sociology 19 (3): 380-382.

Tenopir, Carol. 2007. Web 2.0: Our Cultural Downfall? Library Journal 132 (20): 36.

Tönnies, Ferdinand. 1957. Community and Society. New York: Courier Dover Publications.

Tsekeris, Charalambos and loannis Katerelos. 2012. Web 2.0, Complex Networks and Social Dynamics. Contemporary Social Science 7 (3): 233-246.

Urry, John. 2000. Sociology Beyond Societies. London: Routledge.

Vandenberghe, Frederic. 1999. "The Real is Relational": An Epistemological Analysis of Pierre Bourdieu's Generative Structuralism. Sociological Theory 17 (1): 32-67. 
Vespignani, Alessandro. 2009. Predicting the Behavior of Techno-Social Systems. Science 325 (5939): 425-428.

Wellman, Barry. 1983. Network Analysis: Some Basic Principles. Sociological Theory 1 (1): 155-200.

Wellman, Barry and Barry Leighton. 1979. Networks, Neighborhoods, and Communities Approaches to the Study of the Community Question. Urban Affairs Review 14 (3): 363-390.

White, H. C. 1992. Identity and control: A Structural Theory of Social Action. Princeton: Princeton University Press.

\section{About the Author}

Charalambos Tsekeris

Prof. Charalambos Tsekeris (Brunel, Panteion) is currently Research Associate at the Research Centre for Greek Society of the Academy of Athens and at the Anti-Corruption Centre for Education and Research of Stellenbosch University. He has the title of Professor Extraordinary at the School of Public Leadership, Stellenbosch University, of Senior Researcher at the Laboratory of Virtual Reality, Internet Research \& E-Learning (Panteion University), and of Research Professor at Aegean College, Athens, Greece. He is also directing the Aegean Research Centre (Aegean College) and lecturing at the National and Kapodistrian University of Athens (Department of Communication and Media Studies), the Air Force Command and Staff College (AFCSC), and the Hellenic Naval Staff and Command College, Athens, Greece. His current research interests involve relational approaches in the social science, cyberculture and virtual communities, chaos and complexity science, computational research methods and techniques, human complex systems and psychosocial networks. He is the coeditor of The Social Dynamics of Web 2.0 (Routledge 2014) and editor of Revisiting the Self: Social Science Perspectives (Routledge 2015).Corresponding email: tsekeris@gmail.com. 